\title{
THREE MILE ISLAND: THE MANAGEMENT COMMUNICATION ROLE
}

\author{
J.C. Mathes \\ Professor of Technical Sommunication, College of Engineering, University of Michigan, Ann Arbor, MI 48109 (U.S.A.)
}

\section{ABSTRACT}

The accident at the Three Mile Island Unit 2 nuclear reactor was the result of a sequence of events that, in part, can be interpreted to have resulted from ineffective management communication procedures. An analysis of the ineffectiveness of these particular procedures yields suggestions that are important for improving nuclear safety. They are also important for improving management communication in general.

Eighteen months before the accident an engineer and manager in Babcock \& Wilcox $(B \& W)$, the firm which designed the nuclear power plant at Three Mile Island (TMI), re- commended changes in operator instructions at nuclecir power plants designed by $B \& W$ which, if they had been followed by the operators at TMI, could have prevented the accident. These instructions were never issued by $B \& W$ because inefficient management communication procedures impeded timely decision-making. Essentially, the lines of communication did not complement the decisionmaking process. Additionaliy, management had not established an appropriate communication environment and effective communication practices.

\section{THE COMMUNICATION FAILURE}

The transient that was occurring at Three Mile Island Unit 2 (TMI-2) on the morning of 28 March 1979 evolved into a serious accident when the nuclear power plant operators misinterpreted the pressurizer water level indicator and thus mistakenly terminated the high pressure injection system. The high pressure injection system had been automatically initiated by the emergency core cooling sys. tem (ECCS) when the reactor coolant system pressure had fallen as a result of a pressurizer relief valve which had stu $k$ open.

One of the most important questions raised in the numerous studies of the accident was: why did the operators misinterpret the pressurizer water level indicator? The consensus of opinion was that they had not been pro- vided with the necessary information because engineers and managers in Babcock \& Wilcox (B\&W), the company that had designed the reactor at Three Mile Island (TMI), had failed to communicate effectively. In this context, then, the accident at Three Mile Island was precipitated by a management communication failure [1].

In November 1977, about 18 months before the accident at TMI, a B\&W engineer, Mr. J.J. Kelly, and manager, Mr. B.M. Dunn, formulated operating instructions that "would have provided pertinent, meaningful guidance to the operators at TMI-2 and might have prevented them from taking the actions that ultimately resulted in substantial damage" [2]. Because these instructions were first formulated 18 months before TMI but then never forwarded to the utility's nuclear reac- 
tor operators, the Nuclear Regulatory Commission Special Inquiry Group concluded "that the failure of $\mathrm{B} \& W$ to provide guidance reconmmended by [the engineers] was primarily the result of a gross failure by several individuals, including [the engineers], to communicate effectively, and ineffective management practices that resulted in this issue not being adequately addressed" [3].

The question to ask is: why did the management communication process in B\&W fail to supply the operators at nuclear power plants using $\mathrm{B} \& \mathrm{~W}$ equipment with the necessary information? The studies of the accident do not explore this question [4]. The answers to this question, however, are important for the improvement of the safety of nuclear power plant operations. They are also important for the improvement of management communication in general. Some of these answers are to be found in the testimony by B\&W engineers and managers before the President's Commission on the Accident at Three Mile Island and by an analysis of the memoranda themselves [5].

\section{THE COMMUNICATION PROCESS}

My analysis of the management communication failure that contributed to the accident at TMI begins with an event at the DavisBesse nuclear reactor near Toledo, Ohio, on 14 September 1977. On that date, "an event occurred that is similar in many respects to the TMI-2 incident" [6]. In response to this event at Davis-Besse, Mr. B.M. Dunn, the man- ager of the Emergency Core Cooling System Analysis department of B\&W, wrote a memorandum in which he said, "Had this event occurred in a reactor at full power with other than insignificant burnup it is quite possible, perhaps probable, that core uncovery and possible fuel damage would have resulted." Over a year before TMI, therefore, he recommended that revised operator instructions be issued to only "allow for termination of high pressure injection" under clearly specified conditions [7]. His recommendations, however, were not acted upon until after the accident at TMI.

This management communication process was initiated on 23 October 1977 but not completed until 14 April 1979 (Fig. 1) [8] . On 23 October 1977 an engineer in B\&W, Mr. J.J. Kelly, decided that his company should issue changes in instructions to be followed by the operators in the control rooms at the nuclear plants designed by $B \& W$ for public utilities. On 1 November 1977, therefore, he wrote a memorandum in which he recommended guidelines for nuclear plant operators on when the high pressure injection system could be safely shut down. On 10 November 1977, Mr. F. Walters, a supervisor in Plant Performance Services, responded with a memorandum in which he objected to Mr. Kelly's recommended changes in operator instructions because he felt that the system would go "solid" (the pressurizer would fill with water) [9]. Nothing further happened at that time.

After several months, Mr. B.M. Dunn followed up with his memorandum in which he recommended implementation of essentially

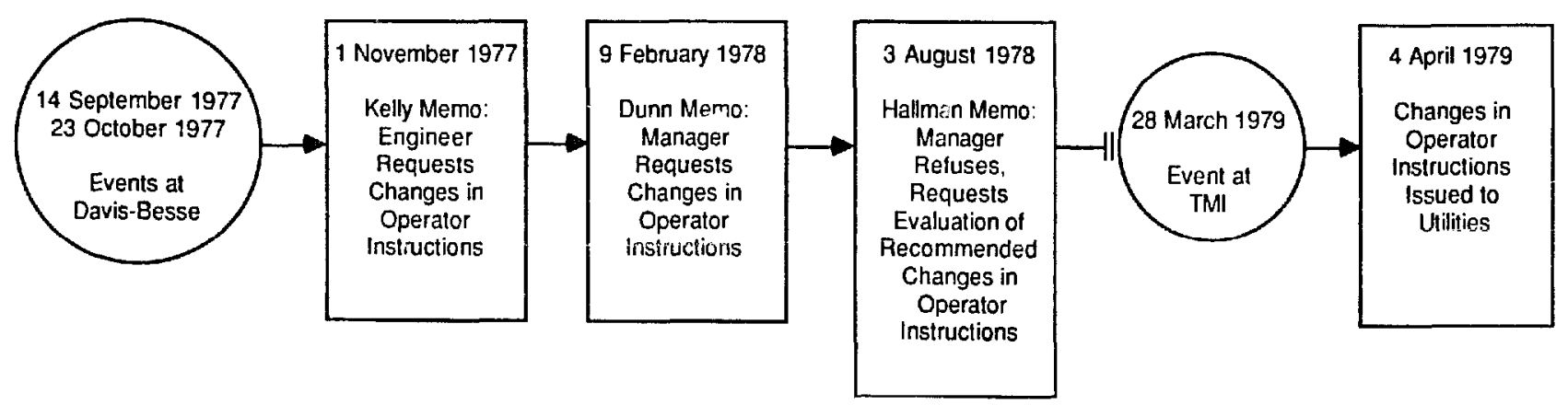

Fig. 1. The inefficient management communication process in regard to changes in operator instructions. 
the same guidelines requested by Mr. Kelly. He mentioned the probability of core uncovery and said, "I believe this is a very serious matter and deserves our prompt attention and correction." Mr. Walters sent a representative to meet with Mr. Dunn to discuss the memorandum. A week later, on 16 February 1978, Mr. Dunn wrote a second memorandum in which he made slight changes in his recommended guidelines for operation of the high pressure injection safety cooling system. Nothing further happened for several months, although Mr. Dunn and Mr. Kelly testified that they assumed the guidelines they had recommended finally had been forwarded to nuclear plant operators.

About six months later, on 3 August 1978, Dr. B.F. Hallman, the manager of Plant Performance Services, responded to the Dunn memoranda. He wrote a memorandum stating that he had not issued the recommended guidelines because of certain concerns about possible negative effects of the changes on some of the piping and core coolant system. He asked Mr. B.A. Karrasch, the Manager of Plant Integration, "to resolve the issue" of how the high pressure injection system should be used [10]. He followed up with several oral contacts, but nothing further occurred until the accident at Three Mile Island on 28 March 1979. That accident resulted in core uncovery and considerable damage to the fuel cladiding [11]. The guidelines recommended by Mr. Kelly and Mr. Dunn subsequently were issued on 4 April 1979 and revised on 17 April 1979. This concluded the management communication process initiated by Mr. Kelly a year and a half previously.

\section{THE MANAGEMENT FAILURE}

An analysis of the management communication practices within $B \& W$ indicates that the failure of $B \& W$ engineers and managers to issue certain recommendations regarding operation of $B \& W$ reactors was the result of an ineffective management communication system and ineffective communication prac- tices. That is, in many ways the failure of individuals to communicate effectively was due to inefficient organizational procedures rather than to the inability of individuals to conform to organizational expectations. The system rather than the individual seemed at fault.

The management communication procedures within $\mathrm{B} \& W$ had three basic problems [12] :

- the lines of communication did not complement the decision-making process;

- the procedures did not provide for effective feedback;

- the procedures often were quite informal considering the expressed concerns that precipitated the communication process in the first place.

The result was inefficient decision-making.

\section{Inappropriate lines of communication}

This particular communication process should have resulted in some manager making the decision to issue these instructions and then another manager issuing the instructions if the decision were to do so. Thus, a decisionmaking situation provided the communication context. However, the actual lines of communication often did not complement the decision-making process. That is, the coinmunication networks did not parallel the relevant decision-making networks. The result was no decision, although information intermittently was communicated within $B \& W$.

The lines of communication were especially inappropriate for the decision-making process required to act upon the recommendations of the crucial Dunn memoranda (Fig. 2). When the Kelly memorandum failed to elicit a response, Mr. Dunn wrote his memorandum in which he requested changes in the operating instructions on high pressure injection. Written by a manager in "a highly responsible position" [13] - Manager of Emergency Core Cooling Systems Analysis - this memcrandum should have resulted in efficient decision-making and subsequent action.

The purpose of the Dunn memorandum 
was to get positive action "leading to instructions to prevent premature operator termination of high pressure injection" [14]. However, he did not send his memorandum to any person in a position to make the decision to issue changes in operating instructions. He only incidentally sent it to a person in a position to actually issue such instructions. Mr. Dunn was in Engineering and was requesting a decision that would be made in Nuclear Services. Specifically, he was requesting a decision appropriate for Plant Performance Services in Nuclear Services to make and action appropriate for Operating Plant Services and also Training in Nuclear Services to take. However, Mr. Dunn addressed his memorandum to Mr. Taylor, the Manager of Licensing, a department in Engineering. But Mr. Taylor testified that the memorandum had been "misdirected". He had no role in this decision-making process because the role of Licensing was to address issues of plant design; issues of actual plant operation concerned Nuclear Services [15]. In addition, Mr. Dunn distributed his memorandum almost exclusively within Engineering.

Mr. Dunn had requested a decision, but never realized that the decision had never been made, and in fact, had been blocked. Despite a meeting with a member of Nuclear Services after his first memorandum and perhaps a phone call from Mr. Taylor "that Mr. Taylor was redirecting the memo to the nuclear service department" [16], Mr. Dunn phrased his second memorandum as a revision of the first and sent it only to the same persons he had sent his first memorandum to. That is, he again sent the second memorandum, which documented his agreement with changes in his instructions suggested by the Nuclear Services person who had met with him, to Mr. Teylcir rather than to a manager in Nuclear Services. He again had the same ten persons on his distribution list, most of them from Engineer-
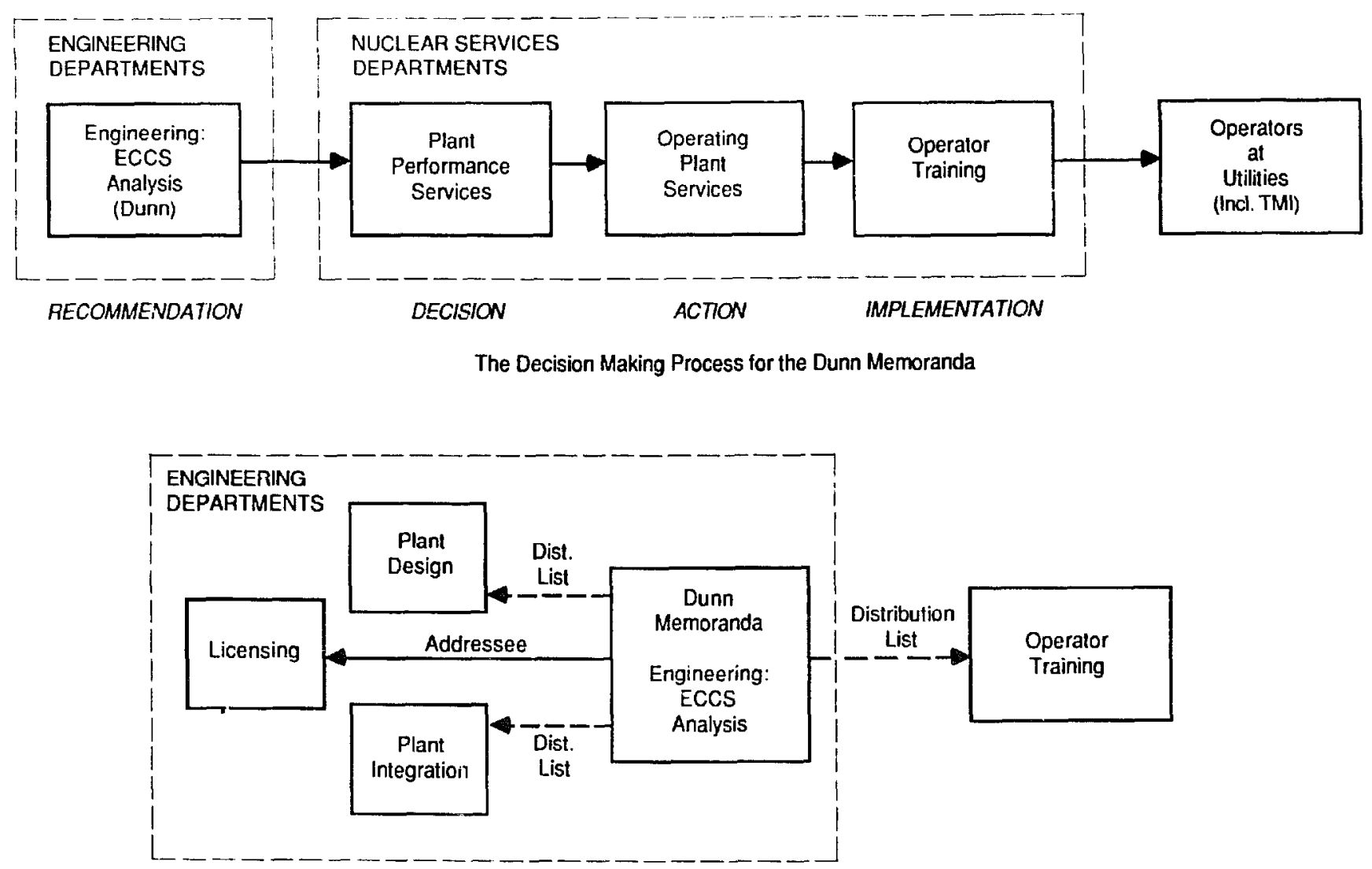

The Lines of Communication for the Dunn Memoranda

Fig. 2. The lines of communication for the Dunn memoranda were inappropriate for the decision-making process. 
ing - and even failed to add the name of the person from Nuclear Services who had met with him.

Thus, the lines of communication for the Dunn memoranda were completely inconsistent with the decision-making process. Not only was the decision never made; Mr. Dunn did not realize it had not been made - before the TMI incident. The communication contexts for all five memoranda primarily included managers and secondarily included scattered supervisors and engineers. Yet none of the persons who received or eventually received the Dunn memoranda and the other memoranda expressed any concern that the communication contexts did not mesh with the decision-making process. If the communication context of the Dunn memoranda had been appropriate for the decision-making process, then perhaps a decision might have been made in time to avoid the accident at TMI.

\section{Ineffective feedback}

An important contributory cause of the communication failure was that the communication process had narrow feedback loops. At crucial times, feeedback loops were entirely missing - yet no one noticed. The Walters memorandum provided an extremely narrow feedback loop. He sent it only to Mr. Kelly and to a person within Nuclear Services who had been on the Kelly distribution list. He did not distribute it to the five managers who had been on the Kelly distribution list or to Mr. Kelly's supervisor. The second Dunn memorandum elicited no feedback, so Mr. Dunn assumed the action he had requested had been taken. To him, lack of feedback signalled positive decision-making.

In general, the communication process was assumed to be linear, with few or no feedback loops established or expected on the part of most of the important actors. When Mr. Karrasch received the important Hallman memorandum, he sent it to one of his engineers within Plant Integration with a note to "follow up" and take "appropriate" action [17].
He then seems to have dismissed the Hallnıan memorandum from his mind until repeated telephone calls from Dr. Hallman several months later. The Hallman memorandum itself had a very narrow communication context, failing to provide feedback to most persons on Dunn's distribution list and to Mr. Dunn himself.

The failure to provide and to expect effective feedback in the communication process can be attributed to inefficient management communication procedures rather than to inefficient individual practices. No one testified that they were expected to have acted differently than they actually had, and in July $1979 \mathrm{Mr}$. Karrasch testified he had "not yet made an investigation" of the breakdowns in communication within his division [18] .

Decision-making, however, is never a cutand-dried, predetermined process. Without communication feedback loops, the decisionmaking process is open ended rather than systematic. It lacks an integrated sequence of reasoned judgments by responsible individuals. Unless management procedures provide for communication feedback loops, important decision-makers such as Mr. Karrasch may "just that quickly, [dispose] of this piece of paper crossing my desk" [19] .

\section{Informal procedures}

Management communication within B\&W also was strikingly inconsistent. In retrospect, despite what seems to have been an important decision-making situation, the communication process was an indiscriminate mixture of informal and formal. That is, oral and handwritten communications were intermixed with typed memoranda that had headings, subject lines, and distribution lists. Mr. Walters wrote a handwritten response to the Kelly memorandum, even though he had been delegated the responsibility for acting on it. Mr. Karrasch eventually gave an oral response to the very important Hallman memorandum. The management communication procedures were inefficient in this regard because at the time these responses to typed memoranda were considered sufficient. 
The Hallman memorandum specifically requested the manager of one department to resolve a legitimate technical dispute between the managers of two other departments. The issues were raised in two written memoranda, the Dunn and Hallman memoranda. Yet, Mr. Karrasch, the manager who was asked to resolve the issue, and Dr. Hallman, the manager who requested his opinion, seemed to have felt that an oral opinion was sufficient. (In addition, Mr. Karrasch did not feel obliged to provide feedback to the third manager, Mr. Dunn.)

Oral and handwritten communications seem inappropriate in a decision-making process that involves changes in the behavior of an organization. Oral communication does not provide the documentation necessary to support, explain, and implement changes in actions, operations, and goals. Informal handwritten notes also cannot carry the burden of communicating actual judgments (as opposed to incidental advice) in a decision-making process. Yet Mr. Karrasch said that documentation was not "required by our procedures" even though he, an important manager, had been asked to decide [20]. Thus, not only was the indiscriminate mixture of oral, handwritten, and typewritten communication inappropriate; the uses themselves of oral and handwritten communication were inappropriate.

\section{MANAGEMENT'S COMMUNICATION RESPONSIBILITY}

Managers, supervisors, and engineers should realize the intrinsic role of written communication in the decision-making process and pattern their organizational behavior as communicators on that role. In regard to nuclear plant safety specifically, effective management communication procedures are necessary to implement some of the improvements called for in the Nuclear Regulatory Commission's TMI Action Plan. They are needed to assure that "operating information pertinent to plant safety originating both within and outside the utility organization is continually supplied to operators and other personnel and is incorporated into training and retraining programs." They should implement "organizational responsibilities for review of operating experience, the feedback of pertinent information to operators and other personnel," and "the administrative and technical review steps necessary in translating recommendations by the operating experience assessment group into plant actions" [21]. Such communication should be formalized to overcome the inertia of the daily routine and the various conflicts of objectives and tasks that impede decisions from being made efficiently and optimally.

In general, written communication processes should complement decision-making processes. The relevant organizational communication procedures should be patterned after the decision-making structures, and individual communication should implement the particular decision-making structure appropriate for the specific purpose of the communication. That is, management communication for decision-making purposes must be distinguished from the various information flows and documentation that enable an organization to function routinely. Management communication functions to enable an organization to adapt, to change, to meet needs. Each specific communication act meets a unique organizational need. It should be performed, however, according to appropriate and effective management communication procedures.

It is the role of management to provide an appropriate communication environment and establish effective report writing procedures. Individuals respond to particular problems and decisions. They do so, however, according to the environment in which they are communicating and according to established communication procedures. When these procedures are not the appropriate procedures, they usually inhibit rather than enhance the decision-making process. Fundamentally, the B\&W example illustrates how an inappropriate environment and ineffective procedures can prevent the most well intentioned com- 
munication from contributing to effective decision-making. Even such a seemingly minor procedure as lack of communication feedback on a memorandum can introduce significant inefficiencies and disturbances into the decision-making process.

Establishing effective communication procedures is a matter of organizational design, not of individual initiative. Effective communication procedures must become part of the routine, the norm, the expected way for individual engineers and managers and other professionals to behave in an organization. This is management's communication responsibility.

\section{ACKNOWLEDGEMENTS}

I wish to thank Ms. Karen Steinke and Mr. Michael Harris for their contributions to this analysis while they were graduate students in nuclear engineering at The University of Michigan. I also wish to thank the reviewers of this manuscript for their many helpful criticisms and suggestions.

\section{REFERENCES AND NOTES}

1 The accident at Three Mile Island had numerous "causes." It was the end result of a series of events, a discrete sequence of which concerns the failures in management communication that $I$ discuss in this article. The most that can be said is that if the operators at TMI-2 had received the recommended changes in operator instructions and had implemented those changes during the transient, then the accident might not have happened or might not have been as severe as it was.

2 "Three Mile Island: A Report to the Commissioners and to the Public," Nuclear Regulatory Commission Special Inquiry Group, Mitchell Rogovin, director, II: 1 (Washington, DC: January 1980), p. 161. This is the "Rogovin Report."

3 Rogovin Report, p. 161.

4 The communication process I analyze in this paper is described in many studies of the accident at Three Mile Island, including the Rogovin Report. These studies, however, limit their concern prinarily to the fact that there were communication problems within B\&W. None of the studies analyzes the proress in depth from the communication point of view in order to determine why it was ineffective. Thus, this additional analysis could prove useful.

5 Transcript of Proceedings, President's Commission on the Accident at Three Mile Island, Public Hearing, July 18, 1979, and Public Hearing, July 19,1979 . The two hearings are paged consecutively as one report. All memoranda I refer to in this article are exhibits in the Transcript. The Transcript is available for reference at the Public Document Room of the Nuclear Regulatory Commission (Washington, DC) and can be ordered through it.

6 "Staff Report on the Generic Assessment of Feedwater Transients in Pressurized Water Reactors Designed by the Babcock \& Wilcox Company," NUREG-0560, Office of Nuclear Reactor Regulation, U.S. Nuclear Regulatory Commission, Washington, DC, May 1979, pp. 3-12. Other reports that analyze this aspect of the accident come to the same conclusion.

7 "Exhibit No. 3" (Memo from Bert Dunn to Jim Taylor), Transcript of Proceedings. This is the Dunn memorandum of 9 February 1978. (The second Dunn memorandum is "Exhibit No. 4.")

8 This communication process is summarized in several sources, such as the Rogovin Report (II: 1, pp. 157-161). My discussion is based on an analysis of the testimony and memoranda in the Transcript of Proceedings. Various B\&W managers and engineers during the testimony presented their explanations and interpretations of these memoranda and communication events. I summarize the process here for persons who do not have easy reference to the Rogovin Report.

9 "Exhibit No. 2" (Letter from J.F. Walters to J.J. Kelly)

10 "Exhibit No. 5" (Memo from D.F. Hallman to B.A. Karrasch).

11 There was no actual "core-melt" at TMI, that is, no actual meltdown of some of the fuel itself. Instead, what seems to have melted was only the "cladding" that contained the fuel. The clean-up at TMI-2 has progressed to the point where cameras have been inserted into the core to inspect the damage. I am indebted to Mr. Gerald Koupal, Bechtel Power Corporation, for this information in his seminar, "Three Mile Island Update," presented to the Nuclear Engineering Department of the University of Michigan, 4 November 1983.

12 In my analysis I am assuming a management model primarily based on Hertert A. Simon, Administrative Behavior, third edition (New York: The Free Press, 1976), in which he says (p. 15): "there is nothing to guarantee that advice produced at one point in an organization will have 
any effect at another point in the organization unless the lines of communication are adequate to its transmission, and unless it is transmitted in such a form as to be persuasive." I am assuming that the decision-making context for this particular communication situation makes the Simon model more appropriate than other management models, such as those discussed by James G. March and Zur Shapria, "Behavioral Decision Theory and Organizational Decision Theory," in Gerardo R. Ungson and Daniel N. Braunstein (Eds.), Decision Making, (Boston: Kent, 1982), pp. 92-115. I also am assuming a communication model based on my own book (with Dwight W. Stevenson), Designing Technical
Reports: Writing for Audiences in Organizations (Indianapolis: Bobbs-Merrill, 1976).

13 Transcript of Proceedings, p. 92.

14 Transcript, p. 61.

15 Transcript, p. 184.

16 Transcript, p. 68.

17 Transcript, p. 241.

18 Transcript, p. 248.

19 Transcript, p. 241.

20 Transcript, p. 255.

21 Clarification of TMI Action Plan Requirements, NUREG-0737, Division of Licensing, Office of Nuclear Reactor Regulation, Nuclear Regulatory Commission, November 1980, p. 3-47. 